\section{S95 CLINICAL OUTCOMES OF ASPERGILLUS DISEASE PHENOTYPES IN ADULT CYSTIC FIBROSIS PATIENTS}

${ }^{1} \mathrm{U}$ Collier, ${ }^{1} \mathrm{RJ}$ Bright-Thomas, ${ }^{2} \mathrm{C}$ Baxter, ${ }^{3} \mathrm{M}$ Richardson, ${ }^{1} \mathrm{AM}$ Jones. ${ }^{1}$ Manchester Adult Cystic Fibrosis Centre, Manchester, UK; ${ }^{2}$ University Hospitals Leicester NHS Trust, Leicester, UK; ${ }^{3}$ Mycology Reference Centre Manchester, Manchester, UK

\subsection{6/thoraxjnl-2017-210983.101}

Objectives Aspergillus disease in cystic fibrosis (CF) patients has been proposed to encompass 4 classes: Class 1; No disease, Class 2; Allergic Bronchopulmonary Aspergillosis (ABPA), Class 3; Aspergillus sensitised, Class 4; Aspergillus Bronchitis. ${ }^{1}$ The clinical consequence of non-ABPA Aspergillus disease in $\mathrm{CF}$ is not fully understood. We evaluated the survival of patients with different classes of Aspergillus disease who were diagnosed as part of Baxter's work between 2008-2011 in order to determine the clinical consequences of the different pheonotypes of disease.

Methods A retrospective case note analysis was undertaken for all 129 patients from the Baxter et al. patient cohort. Survival outcomes were documented for all patients, and baseline demographics including age, gender, $\mathrm{FEV}_{1}$, BMI and co-pathogens were collected. Any patients who received double lung transplantation or who moved away from the unit during this time were identified. The best $\mathrm{FEV}_{1}$ for each year of follow up, $\mathrm{FEV}_{1}$ closest to annual consent date, and BMI were collected for each year of follow in every patient until the current day, or date of death, transplant, or move away. Data was tested for normality and between group comparisons were calculated with one-way anova. Survival was assessed with Kaplan Meier and re-analysed with Cox Regression to adjust for other prognostic factors.

Results There was no statistical significance in survival rates between the 4 classes of Aspergillus disease ( $\mathrm{P}$ value 0.521). The sole predictor of survival was baseline $\mathrm{FEV}_{1} \%$ predicted at time of diagnosis ( $\mathrm{P}$ value $<0.001$ ).

Conclusions There was no statistically significant difference in survival for CF patients with Aspergillus disease over 6-8 years follow up. Further work is being undertaken to continue monitoring and reclassify disease phenotype in this patient cohort.

\section{REFERENCE}

1. Baxter et al. J Allergy Clin Immunol 2013:132(3).

\section{S96 AN OPEN-LABEL EXTENSION (EXT) STUDY OF LUMACAFTOR/IVACAFTOR (LUM/IVA) THERAPY IN PATIENTS AGED 6 TO 11 YEARS WITH CYSTIC FIBROSIS (CF) HOMOZYGOUS FOR F508DEL-CFTR}

${ }^{1} \mathrm{M}$ Chilvers, ${ }^{2} \mathrm{~S}$ Tian, ${ }^{2} \mathrm{G}$ Marigowda, ${ }^{2} \mathrm{M}$ Bsharat, ${ }^{2} \mathrm{C}$ Hug, ${ }^{3} \mathrm{M}$ Solomon, ${ }^{4} \mathrm{P}$ Black ${ }^{5} \mathrm{M}$ Rosenfeld, ${ }^{6} \mathrm{G}$ Sawicki, ${ }^{7} \mathrm{~J}$ Hoppe. ${ }^{1}$ British Columbia Children's Hospital, Vancouver, Canada; ${ }^{2}$ Vertex Pharmaceuticals Incorporated, Boston, US: ${ }^{3}$ The Hospital for Sick Children, Toronto, Canada; ${ }^{4}$ The Children's Mercy Hospital, Kansas City, US; ${ }^{5}$ University of Washington School of Medicine, Seattle, US; ${ }^{6}$ Harvard Medical School, Boston, US; "University of Colorado School of Medicine, Aurora, US

10.1136/thoraxjnl-2017-210983.102

Objective Lumacaftor/Ivacaftor (LUM/IVA) was well tolerated and had beneficial effects on lung function, sweat chloride $(\mathrm{SwCl})$, and body mass index (BMI) in a 24 week, open-label study (VX15-809-011B [011B]) in patients aged 6 to 11 years with cystic fibrosis (CF) homozygous for F508del. We report 36 weeks of additional safety and efficacy data in an ongoing 96 week extension (EXT) study (VX15-809-110; NCT02544451).

Methods Eligible patients from 011B received LUM $200 \mathrm{mg} / \mathrm{IVA}$ $250 \mathrm{mg}$ every 12 hours (q12h; 6-11 years) or LUM $400 \mathrm{mg} / \mathrm{IVA}$ $250 \mathrm{mg} \mathrm{q} 12 \mathrm{~h}$ ( $\geq 12$ years). Primary endpoint was safety. Secondary endpoints included changes in $\mathrm{SwCl}$ and lung clearance index based on lung volume turnover required to reach $2.5 \%$ of starting $\mathrm{N}_{2}$ concentration $\left(\mathrm{LCI}_{2.5}\right)$ through week 24 , and BMI and percent predicted $\mathrm{FEV}_{1}\left(\mathrm{ppFEV}_{1}\right)$ through week 36.

Results Of the 49 enrolled patients (mean age [SD], 9.2 [1.48] years), 47 completed 36 weeks of the EXT study. Adverse events (AEs) were reported in $91.8 \%$ of patients $(34.7 \%$ mild; $49.0 \%$ moderate). Common AEs (cough, $\mathrm{n}=18$; infective pulmonary exacerbation, $n=18$ ) were consistent with expected CF manifestations. Eight $(16.3 \%)$ patients had serious AEs. Four $(8.2 \%)$ patients had $\geq 1$ respiratory AE ( 2 wheezing; 1 bronchial hyperreactivity; 1 dyspnea; 1 respiration abnormal). Six (12.2\%) patients had elevated alanine aminotransferase or aspartate aminotransferase ( $\geq 3$ to $5 \times$ upper limit of normal [ULN], $\mathrm{n}=3 ; \geq 5$ to $8 \times$ ULN, $\mathrm{n}=1 ; \geq 8 \times$ ULN, $\mathrm{n}=2)$. No drug discontinuations were due to AEs. Changes from $011 \mathrm{~B}$ baseline (BL) in $\mathrm{ppFEV}_{1}$ and SwCl were similar to those at $011 \mathrm{~B}$ week 24 (Table). BMI continued to improve. $\mathrm{LCI}_{2.5}$ improvements were stable through EXT week $4(\mathrm{n}=18)$; values at EXT week 24 in a reduced sample size $(n=12)$ were similar to those at $011 \mathrm{~B} \mathrm{BL}$.

Conclusion LUM/IVA was well tolerated for up to 60 weeks in patients aged 6 to 11 years, with no new safety concerns compared with previous LUM/IVA studies conducted in this patient population. LUM/IVA was associated with improved BMI and maintenance of lung function.

Please refer to page A257 for declarations of interest in relation to abstract $\mathbf{S 9 6 .}$

\begin{tabular}{|c|c|c|c|c|c|}
\hline \multirow[t]{2}{*}{ Parameter } & \multirow{2}{*}{$\begin{array}{l}\text { Study 011B } \\
\text { baseline, mean } \\
(\mathrm{SD})^{\mathrm{a}}\end{array}$} & \multicolumn{4}{|c|}{$\begin{array}{l}\text { Absolute change from 011B baseline with } \\
\text { LUM/IVA, mean (SD) }\end{array}$} \\
\hline & & $\begin{array}{l}\text { Study 011B } \\
\text { wk } 24^{\mathrm{a}}\end{array}$ & EXT wk 4 & $\begin{array}{l}\text { EXT wk } \\
24\end{array}$ & $\begin{array}{l}\text { EXT wk } \\
36\end{array}$ \\
\hline $\begin{array}{l}\text { ppFEV }{ }_{1} \text {, } \\
\text { percentage } \\
\text { points }\end{array}$ & $91.4(13.7) n=57$ & $\begin{array}{l}2.4(10.2) \\
n=53\end{array}$ & $\begin{array}{l}1.5(12.8) \\
n=47\end{array}$ & $\begin{array}{l}2.1(11.0) \\
n=46\end{array}$ & $\begin{array}{l}1.6(9.8) \\
\mathrm{n}=43\end{array}$ \\
\hline $\mathrm{BMI}, \mathrm{kg} / \mathrm{m}^{2}$ & $16.89(1.93) n=58$ & $\begin{array}{l}0.65(0.69) \\
n=56\end{array}$ & $\begin{array}{l}0.71 \\
(0.64) \\
n=48\end{array}$ & $\begin{array}{l}0.91 \\
(0.94) \\
n=47\end{array}$ & $\begin{array}{l}1.17 \\
(1.13) \\
n=47\end{array}$ \\
\hline $\mathrm{SwCl}, \mathrm{mmol} / \mathrm{L}$ & $105.9(10.2) n=58$ & $\begin{array}{l}-25.6 \\
(15.7) n=51\end{array}$ & $\begin{array}{l}-26.0 \\
(13.2) \\
n=43\end{array}$ & $\begin{array}{l}-29.0 \\
(15.7) \\
n=42\end{array}$ & - \\
\hline $\mathrm{LCl}_{2.5}$ & $9.99(2.67) n=25$ & $\begin{array}{l}-0.95 \\
(1.39) n=23\end{array}$ & $\begin{array}{l}-0.82 \\
(1.65) \\
\mathrm{n}=18\end{array}$ & $\begin{array}{l}-0.29 \\
(1.36) \\
n=12\end{array}$ & - \\
\hline
\end{tabular}

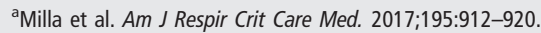

\section{Improvements in lung cancer treatment}

\section{7 \\ MANAGEMENT OF EARLY STAGE LUNG CANCER IN THE ELDERLY: AN OBSERVATIONAL STUDY}

MPT Kennedy, K Franks, A Brunelli, MEJ Callister. Leeds Teaching Hospitals NHS Trust, Leeds, UK

10.1136/thoraxjnl-2017-210983.103 
Introduction Elderly patients are less likely to receive radical treatment for lung cancer. Palma et al (2010) demonstrated an increase in radical treatment rates for patients aged $\geq 75$ years in Holland following the introduction of Stereotactic Ablative Radiotherapy (SABR), without reduction in surgical resections. This was associated with improved overall survival. There are international differences in radical treatment rates and outcomes in lung cancer. We aim to evaluate the changes in lung cancer treatment and outcomes following the introduction of SABR in the UK.

Methods This is a retrospective observational study at a large UK teaching hospital. Data for patients diagnosed over seven years (2008-2014) were analysed from a local dataset maintained for the National Lung Cancer Audit. SABR was introduced for lung cancer in Leeds in 2010. Statistical analyses were performed using Chi-square, t-test and Kaplan Meier survival analysis.

Results There were 1874 new diagnoses of lung cancer in patients aged $\geq 75$ years, accounting for $45.3 \%$ of all new diagnoses. Comparing patients $\geq 75$ years pre-SABR (20082009) and post-SABR (2011-2014), there was an increase in the proportion of early stage disease (stage I-IIA $22.5 \%$ to $29.2 \%, \mathrm{p}=0.0054)$. Of the 502 patients with early stage disease, there was no change in performance status (PS 0\%-2 $68.4 \%$ to $63.3 \%, \mathrm{p}=0.2468$ ) or age at diagnosis (median (IQR) 81.1 (78.0-84.3) to $80.9(77.7-85.1)$ years, $\mathrm{p}=0.7422)$. Rates of radical radiotherapy/SABR $(12.2 \%$ to $39.2 \%$, $\mathrm{p}<0.001)$ have increased, while surgical resections $(28.9 \%$ to $28.5 \%, \mathrm{p}=1.000$ ) have remained stable and the proportion of patients receiving palliative treatment/best supportive care (BSC) has decreased $(58.8 \%$ to $32.3 \%, \mathrm{p}<0.001)$ (figure 1). Median overall survival has increased (518 to 687 days, $\mathrm{p}=0.0016$ ).

Discussion The proportion of elderly patients being diagnosed with early stage lung cancer is increasing. There has been no significant change in the demographics of those with early stage disease. Following the introduction of SABR in 2010, there has been an increase in radical radiotherapy treatment for elderly patients with early stage disease, with no sustained change in surgical resection rates and increase in overall rates of radical treatment. This was associated with a significant improvement in overall survival.

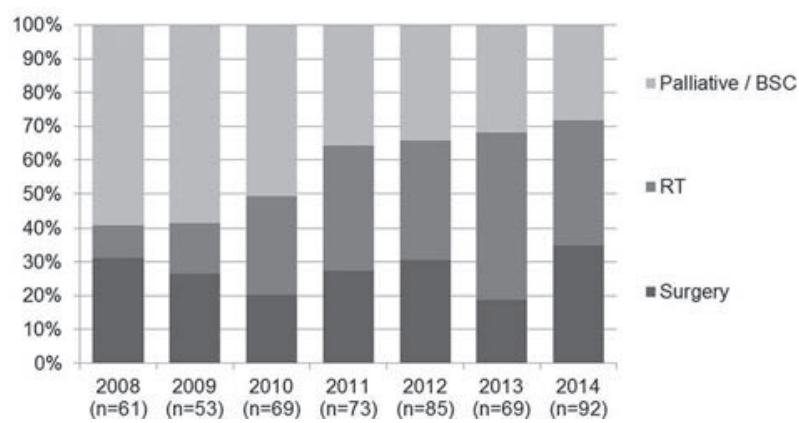

Abstract 597 Figure 1 Treatment of stage I-IIA lung cancer in patients $\geq 75$ years.

\section{S98 TREATMENT PATTERNS AND SURVIVAL OUTCOMES OF STAGE IIIA (N2) NON -SMALL CELL LUNG CANCER IN ENGLAND}

${ }^{1} \mathrm{JB}$ Adizie, ${ }^{2} \mathrm{~A}$ Khakwani, ${ }^{2} \mathrm{P}$ Beckett, ${ }^{2} \mathrm{~N}$ Navani, ${ }^{2} \mathrm{~S}$ Harden, ${ }^{2} \mathrm{~W}$ Woolhouse. ${ }^{1}$ Heart of England NHS Foundation Trust, Birmingham, UK; ${ }^{2}$ Care quality improvement department, Royal College of Physicians, London, UK

\subsection{6/thoraxjnl-2017-210983.104}

Introduction The optimal management of lung cancer patients with metastatic involvement of the ipsilateral mediastinum (N2 disease) remains controversial. Randomised controlled trials have failed to demonstrate superiority of one bimodality strategy over another (chemotherapy plus surgery versus chemotherapy plus radiotherapy). There is little knowledge of real world experience of the uptake of different treatment regimens and the corresponding survival outcomes. Data collected via the National Lung Cancer Audit (NLCA) and linked for the first time to the national radiotherapy dataset (RTDS) allow us to describe the treatment patterns and outcomes of patients with N2 disease in England.

Methods Patients diagnosed with stage T1-3, N2, M0 nonsmall cell lung cancer between 1 st January 2015 and 31 st December 2015 were identified. The dose and schedule of radiotherapy treatments described in the RTDS were used to determine if the radiotherapy was given with radical or palliative intent. The proportion of patients alive at the time of data analysis (9-21 months from diagnosis) were calculated according to treatment category.

Results 2305 of 36025 (6.4\%) patients met the inclusion criteria. The proportion of patients receiving each treatment

Abstract S98 Table 1 Treatment patterns and survival outcomes of stage 3a (N2) lung cancer ( $n=2305)$

\begin{tabular}{llll}
\hline Groups & $\begin{array}{l}\text { Number } \\
(\mathbf{n})\end{array}$ & $\begin{array}{l}\text { Percentage } \\
(\%)\end{array}$ & $\begin{array}{l}\text { Survival } \\
(\%)\end{array}$ \\
\hline Group 1: Surgery & 450 & 19.5 & 74.4 \\
Surgery & 165 & 7.2 & 61.8 \\
Surgery and Adjuvant Chemotherapy & 222 & 9.6 & 82.9 \\
Neoadjuvant chemotherapy and surgery & 21 & 0.9 & 90.5 \\
Surgery and Radical Radiotherapy & 5 & 0.2 & 60.0 \\
Triple therapy & 37 & 1.6 & 73.0 \\
& & & \\
Group 2: Radical Radiotherapy & 435 & 18.9 & 63.2 \\
Radical Radiotherapy & 205 & 8.9 & 61.5 \\
Radical Radiotherapy and Chemotherapy & 230 & 10.0 & 64.8 \\
& & & \\
Group 3: Palliative intent treatment & 618 & 26.8 & 41.8 \\
Palliative radiotherapy and chemotherapy & 142 & 6.2 & 36.6 \\
Palliative radiotherapy & 249 & 10.8 & 29.7 \\
Palliative Chemotherapy alone & 227 & 9.8 & 58.2 \\
Group 4: Best Supportive Care (No & 802 & 34.8 & 23.1 \\
treatment) & & & \\
\hline
\end{tabular}

